\title{
THE
}

\section{Captive dolphins, Tursiops truncatus, develop signature whistles that match acoustic features of human-made model sounds}

Jennifer L. Miksis

University of Rhode Island

Peter L. Tyack

John R. Buck

Follow this and additional works at: https://digitalcommons.uri.edu/gsofacpubs

Terms of Use

All rights reserved under copyright.

\section{Citation/Publisher Attribution}

Miksis, J. L., Tyack, P. L., \& Buck, J. R. (2002). Captive dolphins, Tursiops truncatus, develop signature whistles that match acoustic features of human-made model sounds. The Journal of the Acoustical Society of America, 112(2), 728-739. doi: 10.1121/1.1496079

Available at: https://doi.org/10.1121/1.1496079

This Article is brought to you for free and open access by the Graduate School of Oceanography at DigitalCommons@URI. It has been accepted for inclusion in Graduate School of Oceanography Faculty Publications by an authorized administrator of DigitalCommons@URI. For more information, please contact digitalcommons-group@uri.edu. 


\section{Captive dolphins, Tursiops truncatus, develop signature whistles that match acoustic features of human-made model sounds}

Jennifer L. Miksis, Peter L. Tyack, and John R. Buck

Citation: The Journal of the Acoustical Society of America 112, 728 (2002); doi: 10.1121/1.1496079

View online: https://doi.org/10.1121/1.1496079

View Table of Contents: http://asa.scitation.org/toc/jas/112/2

Published by the Acoustical Society of America

\section{Articles you may be interested in}

Differences in acoustic features of vocalizations produced by killer whales cross-socialized with bottlenose dolphins

The Journal of the Acoustical Society of America 136, 1990 (2014); 10.1121/1.4893906

Echolocation range of captive and free-ranging baiji (Lipotes vexillifer), finless porpoise (Neophocaena phocaenoides), and bottlenose dolphin (Tursiops truncatus)

The Journal of the Acoustical Society of America 104, 2511 (1998); 10.1121/1.423757

Whistle matching in wild bottlenose dolphins

The Journal of the Acoustical Society of America 101, 3136 (1997); 10.1121/1.419266

Directional properties of bottlenose dolphin (Tursiops truncatus) clicks, burst-pulse, and whistle sounds The Journal of the Acoustical Society of America 131, 1613 (2012); 10.1121/1.3676694

Bottlenose dolphins (Tursiops truncatus) moan as low in frequency as baleen whales The Journal of the Acoustical Society of America 126, 1552 (2009); 10.1121/1.3177272

Covert underwater acoustic communication using dolphin sounds

The Journal of the Acoustical Society of America 133, EL300 (2013); 10.1121/1.4795219 


\title{
Captive dolphins, Tursiops truncatus, develop signature whistles that match acoustic features of human-made model sounds
}

\author{
Jennifer L. Miksis \\ Biology Department, Woods Hole Oceanographic Institution, Woods Hole, Massachusetts 02543 \\ and Graduate School of Oceanography, University of Rhode Island, Narragansett, Rhode Island 02882 \\ Peter L. Tyack \\ Biology Department, Woods Hole Oceanographic Institution, Woods Hole, Massachusetts 02543 \\ John R. Buck \\ Department of Electrical and Computer Engineering \& School for Marine Science and Technology, \\ University of Massachusetts Dartmouth, 285 Old Westport Road, North Dartmouth, \\ Massachusetts 02747-2300 and Biology Department, Woods Hole Oceanographic Institution, \\ Woods Hole, Massachusetts 02543
}

(Received 30 May 2001; revised 7 April 2001; accepted 28 May 2002)

\begin{abstract}
This paper presents a cross-sectional study testing whether dolphins that are born in aquarium pools where they hear trainers' whistles develop whistles that are less frequency modulated than those of wild dolphins. Ten pairs of captive and wild dolphins were matched for age and sex. Twenty whistles were sampled from each dolphin. Several traditional acoustic features (total duration, duration minus any silent periods, etc.) were measured for each whistle, in addition to newly defined flatness parameters: total flatness ratio (percentage of whistle scored as unmodulated), and contiguous flatness ratio (duration of longest flat segment divided by total duration). The durations of wild dolphin whistles were found to be significantly longer, and the captive dolphins had whistles that were less frequency modulated and more like the trainers' whistles. Using a standard t-test, the captive dolphin had a significantly higher total flatness ratio in 9/10 matched pairs, and in 8/10 pairs the captive dolphin had significantly higher contiguous flatness ratios. These results suggest that captive-born dolphins can incorporate features of artificial acoustic models made by humans into their signature whistles. (C) 2002 Acoustical Society of America. [DOI: 10.1121/1.1496079]
\end{abstract}

PACS numbers: 43.80.Ka, 43.80.Ev, 43.60.Qv [WA]

\section{INTRODUCTION}

Bottlenose dolphins, Tursiops truncatus, produce frequency-modulated signals called whistles. Caldwell and Caldwell (1965) presented data suggesting that each dolphin within a captive group produced an individually distinctive whistle, which they called a "signature whistle." Four independent research groups have studied signature whistles in a total of 132 captive (Caldwell et al., 1990; Janik et al., 1994; Janik and Slater, 1998) and 90 wild dolphins (Sayigh et al., 1990, 1995, 1999; Smolker et al., 1993) for a total of 222 individuals. The setting in which it has been easiest to identify whistles involves temporarily isolating one dolphin. In this setting, the isolated dolphin tends to produce a long series of sound, repeating a whistle over and over. Human judges rate spectrograms of these whistles as similar within an individual's repertoire and highly distinctive across individuals.

In the 1960s, when David and Melba Caldwell initially introduced the signature whistle hypothesis, they believed that each dolphin was only capable of producing one kind of stereotyped whistle, and they called any whistle other than an individual's signature whistle an "aberrant" whistle. However, in settings other than isolation, dolphins produce many other whistle types, such as simple upsweeps, downsweeps, and sinusoidal patterns of modulation, along with variable contours that may not be repeated precisely (Tyack, 1986; Janik and Slater, 1998). The tendency for signature whistles to be produced during isolation suggested to Janik and Slater (1998) that these whistles function as contact calls.

Sayigh et al. (1990) provide evidence that bottlenose dolphins produce signature whistles that develop within a few years of age, and that are stable for decades. At the same time, however, adult dolphins retain remarkable abilities to imitate manmade whistle-like sounds (Caldwell and Caldwell, 1972; Richards et al., 1984). Bottlenose dolphins may spontaneously imitate sounds within a few seconds after the first exposure (Herman, 1980), or after only a few exposures (Reiss and McCowan, 1993). Dolphins can also be trained to imitate manmade whistle-like sounds (Evans, 1967; Richards et al., 1984; Sigurdson, 1993). After experience with imitation training, some dolphins have learned to imitate a model sound immediately after it was first presented. Once a dolphin learns to imitate a sound, the imitation can be incorporated into its vocal repertoire, and the dolphin can produce the sound even when it does not hear the model. This means that dolphins have an open vocal repertoire that can change throughout the lifespan.

Little is known, however, about the role of imitation or vocal matching in the development of signature whistles. 
Most terrestrial mammals appear to inherit acoustic features of their calls (Janik and Slater, 1997). There is usually a strong similarity between calls of parents and offspring, even if they are cross fostered (Owren et al., 1993). By contrast, most dolphin calves develop signature whistles quite different from their parents. Sayigh et al. (1995) found that roughly half of bottlenose dolphin sons develop whistles similar to their mothers, but nearly all daughters and the other half of sons develop different whistles. The lack of similarity in signature whistles of dolphins and their mothers couples with evidence that young dolphins may develop whistles similar to those of a foster mother to suggest that the auditory environment may be more important than inheritance in determining the structure of a dolphin's signature whistle (Tyack and Sayigh, 1997).

Some of the most convincing data for vocal learning in whistle ontogeny stem from comparing the whistles of calves to sounds present in their acoustic environments. Tyack and Sayigh (1997) discuss evidence that two dolphins born in a captive community pool developed whistles very similar to a whistle used by trainers. Most dolphin trainers use a dog whistle to signal a dolphin that it can approach for food after performing a requested task. The sound from these dog whistles is a high-frequency tone with little frequency modulation.

This paper examines the hypothesis that whistle development in captive calves may be influenced by exposure to these flat unmodulated whistles used by trainers. We matched pairs of captive and wild dolphins by age and sex and compared the modulation of whistles produced by these two groups in order to test whether dolphins born in captivity are more likely than wild dolphins to have whistles with little frequency modulation like the unmodulated trainer's whistle. Dolphins were analyzed as pairs matched for age and sex because Caldwell et al. (1990) report a significant increase in frequency modulation with age in captive bottlenose dolphins, and because Sayigh et al. (1995) report strong differences in mother-offspring comparisons of signature whistles of sons vs daughters.

\section{METHODS}

\section{A. Whistle recordings}

Whistles from wild-born dolphins were recorded from a population of Atlantic bottlenose dolphins off the coast of Sarasota, Florida, during capture-release sessions. For a complete description of the study site and the Sarasota capture-release projects, see Scott et al. (1990) and Sayigh et al. (1990). Whistles used in this study were obtained from recordings that cover a 7-year period from 1986-1992. Whistles from the Sarasota population were recorded while the dolphin was placed on a raft for processing. During this time a suction cup hydrophone (designed by Tyack; Tyack, 1985) was affixed to the animal's head slightly behind the blowhole. Recordings made prior to 1989 were made with a Sony TC-D5 or a Marantz PMD-430 stereo tape recorder and used Maxell UDXLII cassette tapes. This system had a frequency response of 30-15000 Hz. Recordings made after
1989 were made with a Panasonic AG-6400 stereo hi-fi VCR using standard VHS tapes, and the frequency response measured 20-20000 Hz.

Whistles from captive-born dolphins were recorded at the Miami Seaquarium over a span of 4 years, 1988-1991. Eight individuals were recorded at the aquarium's "Top Deck" pool, and two individuals were recorded at the "Flipper" lagoon. Top Deck is a cylindrical outdoor pool approximately 6 meters in depth and 27 meters in diameter. The Flipper lagoon is a manmade seawater pool which extends into the Biscayne Bay. Over the course of the study the number of dolphins in Top Deck ranged from 10-14 individuals. Five dolphins were present in the Flipper lagoon. All animals were born in Top Deck. Adults in both pools performed daily shows for the public, and all the dolphins were habituated to interactions with trainers.

Recordings of the Miami Seaquarium dolphins were made using a Realistic hi-fi VHS recorder and Scotch T-120 cassettes or with a Sony TCD3M stereo cassette recorder and Maxell UDXLII tapes. One channel recorded underwater sounds from a modified U.S. Navy sonobuoy mounted in the pool. A microphone fed into the second channel for comments. The frequency response was limited by the hydrophone in both systems and was approximately 100-15000 Hz. The whistles from the wild and captive dolphins were recorded with different equipment, but comparisons of whistle contours made with contact hydrophones in air vs far-field underwater show little difference in the contour.

Dolphins in Top Deck were viewed from either a floating platform or an underwater window during recording sessions. Animals in the Flipper pool were observed from a dock during recordings. Dolphins producing sound were identified through synchronized blowhole movement with the onset of whistle production, bubble streams from the blowhole during the whistle duration, or whistles audible at the surface of the water that could be localized in air. While signature whistles are typically recorded in an isolation setting, our recordings of whistles identified from captive dolphins swimming within large community pools in the Miami Seaquarium were consistent with signature whistles in that each animal was identified producing a distinctive contour.

\section{B. Analysis techniques}

Captive and wild-born dolphins were matched for age and sex and totaled ten pairs (Table I). Half of the pairs were male, half were female, and the ages ranged from 1-35 years. We used a sample of 20 signature whistles from each of these 20 dolphins. The sample size of dolphins was restricted by the number of dolphins that we had recorded and which were born in a facility where we knew that the dolphin had heard trainers' whistles as it developed its signature whistle. The number of whistles from each dolphin was limited by the difficulty of identifying whistles of captive dolphins using the methods employed in this paper. Weeks of observational effort often yielded only a few tens of whistles identified to a particular individual. The maximum number of whistles that could be identified from three of the captive animals was 20; hence, the sample size of 20 whistles was selected to maintain uniformity throughout the study. 
TABLE I. Age, sex, and animal identifications of the ten pairs of wild and captive dolphins matched for age and sex.

\begin{tabular}{lccccccc}
\hline \hline $\begin{array}{c}\text { Animal } \\
\text { name }\end{array}$ & Year of birth & $\begin{array}{c}\text { Captive dolphin } \\
\text { code }\end{array}$ & Sex & $\begin{array}{c}\text { Age } \\
\text { (years) }\end{array}$ & $\begin{array}{c}\text { Wild dolphin } \\
\text { code }\end{array}$ & Year of birth & $\begin{array}{c}\text { Animal ID } \\
\text { number }\end{array}$ \\
\hline Samantha & 1988 & C1 & F & 2 & W1 & 1986 & FB55 \\
Noel & 1988 & C2 & M & 2 & W2 & 1987 & FB22 \\
Dawn & 1975 & C3 & F & 15 & W3 & 1971 & FB90 \\
Dancer & 1980 & C4 & F & 10 & W4 & 1979 & FB25 \\
Ivan & 1983 & C5 & M & 6 & W5 & 1980 & FB32 \\
Tori & 1990 & C6 & F & 1 & W6 & 1986 & FB1 \\
Bebe & 1956 & C7 & F & 35 & W7 & 1953 & FB153 \\
Sundance & 1990 & C8 & M & 1 & W8 & 1988 & FB50 \\
PJ & 1990 & C9 & M & 1 & W9 & 1988 & FB2 \\
Shadow & 1985 & C10 & M & 4 & W10 & 1985 & FB150 \\
\hline \hline
\end{tabular}

Captive-wild pairs were constructed by randomly choosing a wild counterpart for each captive subject from an established database of Sarasota recordings (Sayigh et al., 1995). To prevent bias, pairs were selected before any spectrograms were made. The initial selection and pairing of individuals remained constant throughout the study. Spectrograms were created from whistles digitized on a Kay Elemetrics Corp. model 5500 digital signal processing system at $81920 \mathrm{~Hz}$ with an upper frequency limit of $32 \mathrm{kHz}$ and a dynamic range setting of $42 \mathrm{~dB}$. Spectrograms of whistles from the Sarasota recordings were made from the tapes at a rate of approximately one whistle every $60 \mathrm{~s}$. No such sampling protocol was established for whistles from the captive dolphins because only a limited number of whistles were identified from captive individuals.

Five frequency parameters were measured by hand from the spectrograms (Table II). Minimum, maximum, start, and end frequencies were measured directly from the spectrogram for each wild and captive whistle. Frequency range was calculated from the difference of maximum and minimum frequencies. Three different trainer's whistles were also measured for the same parameters. Each frequency and duration parameter for wild and captive pairs presented in Table II reflects the mean of 20 whistles. Values for the trainers' whistles were based on four recordings of the first kind of whistle used for training and two recordings each for the second and third kinds of trainers' whistles. The total $n=8$ for the trainers' whistles reflects an exemplar from each of the eight trainers using whichever of the three kind of whistles they habitually used.

Contours of the fundamental frequency were obtained using a previously reported contour extractor for Tursiops truncatus whistles (Buck and Tyack, 1993). This contour extractor computes the short-time Fourier transform (STFT) (Oppenheim et al., 1999) for each time interval, or block, of the whistle. The contour extractor chooses the fundamental frequency for each block independently of the other blocks. The fundamental frequency is generally chosen to be the frequency with the strongest energy, except for a few heuristic rules to handle brief segments when the second harmonic contained more energy than the fundamental. These segments most frequently occurred during the start or end of a whistle.

For all the whistles in this study, the STFT blocks were 1024 samples long, corresponding to $12.5 \mathrm{~ms}$, and there was no overlap between adjacent blocks. The FFT size was also 1024 points, yielding an FFT bin size of $80 \mathrm{~Hz}$. Figure 1 shows the time-domain signal, spectrogram, and the extracted contour for three signals-one wild animal whistle, one captive animal whistle, and one trainer's whistle. Since the whistles from wild dolphins were recorded using a contact hydrophone, they tended to have a high signal-to-noise ratio (SNR). Whistles from the captive dolphins tended to

TABLE II. Frequency parameters of whistles measured by hand from the whistle contours. The values for each dolphin are based on the mean of $n=20$. The values for the trainers whistles represent means for each of the three different trainer whistles, as well as a group mean for all of the trainers' whistle recordings $(n=8)$.

\begin{tabular}{|c|c|c|c|c|c|c|c|c|c|c|c|c|c|c|c|}
\hline \multirow[b]{2}{*}{ Pair \# } & \multicolumn{3}{|c|}{ Minimum frequency $(\mathrm{Hz})$} & \multicolumn{3}{|c|}{ Maximum frequency $(\mathrm{Hz})$} & \multicolumn{3}{|c|}{ Start frequency $(\mathrm{Hz})$} & \multicolumn{3}{|c|}{ End frequency $(\mathrm{Hz})$} & \multicolumn{3}{|c|}{ Frequency range $(\mathrm{Hz})$} \\
\hline & Trainer & Captive & Wild & Trainer & Captive & Wild & Trainer & Captive & Wild & Trainer & Captive & Wild & Trainer & Captive & Wild \\
\hline 1 & 4720 & 3920 & 4400 & 6880 & 12800 & 14560 & 4880 & 6000 & 4640 & 5280 & 4640 & 8880 & 2160 & 8880 & 10160 \\
\hline 2 & 6560 & 3200 & 8080 & 9600 & 13040 & 22880 & 6720 & 4720 & 8440 & 6720 & 4240 & 22160 & 3040 & 9840 & 14800 \\
\hline 3 & 7680 & 2720 & 4240 & 10560 & 16960 & 17760 & 7840 & 4880 & 5520 & 7840 & 3120 & 13360 & 2880 & 14240 & 13520 \\
\hline 4 & & 5360 & 7040 & & 17120 & 22640 & & 8240 & 11520 & & 6320 & 18880 & & 11760 & 15600 \\
\hline 5 & & 6000 & 3920 & & 17520 & 17360 & & 9360 & 7040 & & 14320 & 21440 & & 11520 & 13440 \\
\hline 6 & & 4080 & 5840 & & 8880 & 17920 & & 4880 & 6640 & & 4560 & 17680 & & 4800 & 12080 \\
\hline 7 & & 3920 & 3520 & & 17280 & 20800 & & 4720 & 3920 & & 8480 & 9040 & & 13360 & 17280 \\
\hline 8 & & 4320 & 4080 & & 8720 & 14240 & & 4720 & 4320 & & 5520 & 8720 & & 4400 & 10160 \\
\hline 9 & & 4000 & 4880 & & 10640 & 16640 & & 4800 & 7680 & & 5040 & 6560 & & 6640 & 11760 \\
\hline 10 & & 5760 & 4240 & & 17620 & 17360 & & 10800 & 6880 & & 15760 & 8960 & & 11760 & 13120 \\
\hline Average & 5920 & 4328 & 5024 & 8480 & 14048 & 18216 & 6080 & 6312 & 6660 & 6280 & 7200 & 13568 & 2560 & 9720 & 13192 \\
\hline
\end{tabular}



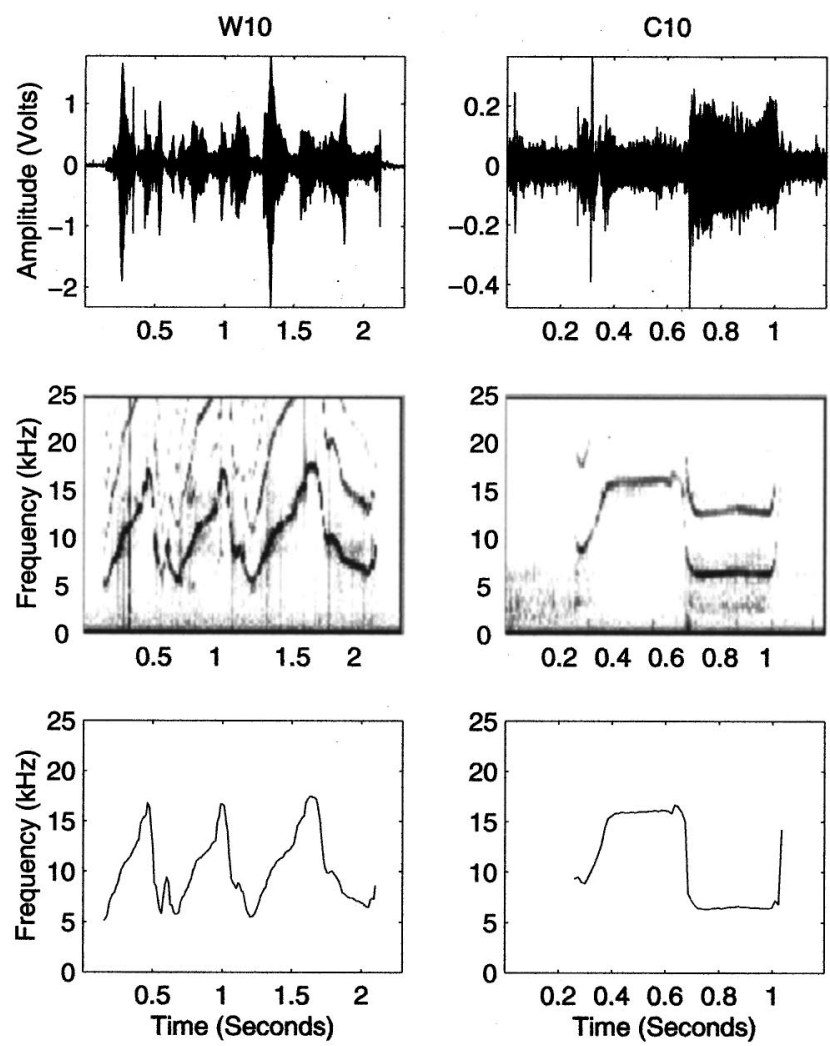

have a lower SNR. For all three signals, the extracted contour follows the fundamental contour of the whistle.

\section{Estimating modulation rate of whistle contours}

This study focused on flatness, or the lack of frequency modulation, in signature whistles. A lack of modulation corresponds to a small or zero slope in the extracted contour of frequency vs time. We defined a time interval as containing an unmodulated or flat whistle segment if the slope of the contour over this interval was below a chosen modulation threshold $\mu$. The method for choosing $\mu$ is described in more detail below. Practically, the measure of flatness implemented for comparison to $\mu$ is the difference of frequencies in adjacent time bins divided by the time interval between the bins. The resolution of this estimate is limited by the FFT bin size $(80 \mathrm{~Hz})$ divided by the STFT block length $(12.5 \mathrm{~ms})$. The minimum change in frequency that this approach could detect is $80 \mathrm{~Hz}$ in $12.5 \mathrm{~ms}$ or $80 \mathrm{~Hz} / 0.0125 \mathrm{~s}=6400 \mathrm{~Hz} / \mathrm{s}$.

This difference of frequencies approximates the slope or time derivative of the frequency contour. This approximation is necessary, because the derivative of a discrete-time signal is, strictly speaking, not well defined. Theoretically, the best estimate of the derivative would be to sample the derivative of the bandlimited interpolation of the original contour, also called bandlimited differentiation. For this study, the first backward difference (Oppenheim et al., 1999) was used as an approximation to this bandlimited derivative. Specifically, if $x[n]$ is the sampled frequency contour for $0 \leqslant n \leqslant N-1$, the derivative signal $y[n]$ is defined to be

$$
y[n]=\frac{x[n]-x[n-1]}{\Delta T},
$$
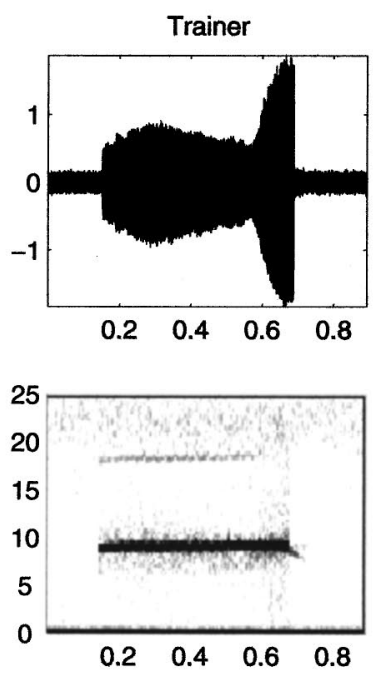

FIG. 1. Wave form (top row), spectrogram (middle row), and contour (bottom row) for a randomly selected whistle from animal W10 (left column), animal C10 (middle column), and the trainer (right column). Note the similarities in the spectrogram and contour between $\mathrm{C} 10$ and the trainer. for $1 \leqslant n \leqslant N-1$, where $\Delta T=1024 / 81920=12.5 \mathrm{~ms}$ is the time interval between the samples of the contour. The backward difference is not in general a good approximation to a bandlimited differentiator. However, if the signal $x[n]$ was highly oversampled such that most of the energy in its discrete-time Fourier transform $X\left(e^{j \omega}\right)$ is concentrated at low frequencies, the backward difference is a reasonable approximation to bandlimited differentiation. The contours studied in this paper are sufficiently oversampled for this approximation to be valid. The errors introduced at moderate to high $\omega$, discrete-time frequency, will not be significant. Once the slope is above our modulation threshold, the segment is considered to be modulated, and not flat. The specific value of the slope is not of interest.

The durations of whistle contours were also measured in order to calculate the ratio of flat segment durations to the duration of the whole whistle. Two different whistle durations were measured. The total duration was measured from the beginning of the whistle to the last element of the contour. Many whistles such as those from C4 and W6 in Fig. 2 had silent gaps within the whistle. A "gap-free" duration was calculated by subtracting the duration of these gaps from the total duration.

Two quantitative measures of the amount of the whistle which is unmodulated are computed from the backward difference $y[n]$. The first, referred to as total flatness, is the ratio of flat segment durations to total gap-free duration; total flatness can also be defined as the fraction of the values of $|y[n]| \leqslant \mu$. Intuitively, this total flatness measure quantifies the percentage of the duration of the whistle which consists of unmodulated signal. In the extreme case of a wholly unmodulated signal, this number should be 1 . The second mea- 

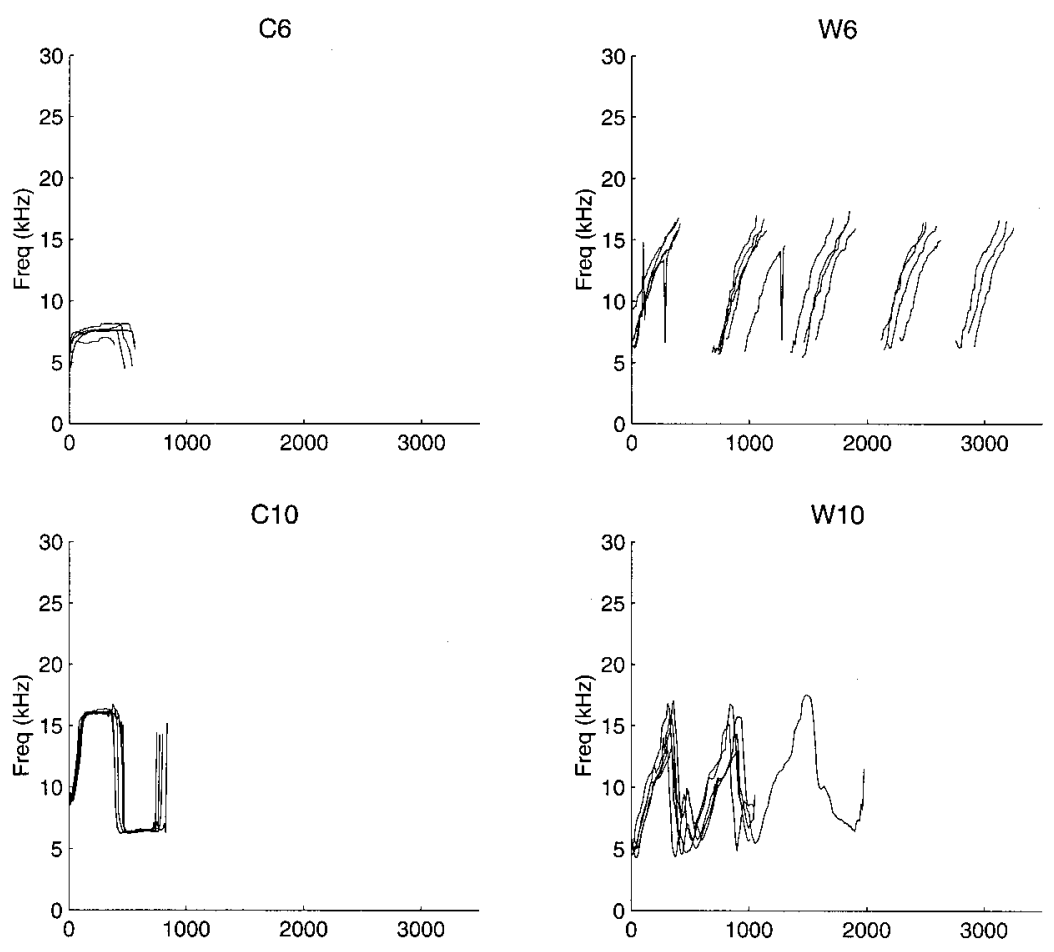

FIG. 2. Contour comparisons for three captive-wild matched pairs. Each graph contains five randomly selected contours from the specified animal. Out of the ten pairs studied, $\mathrm{C} 4-\mathrm{W} 4$ is the only pair in which the wild animal has a longer flat segment in its signature whistle.
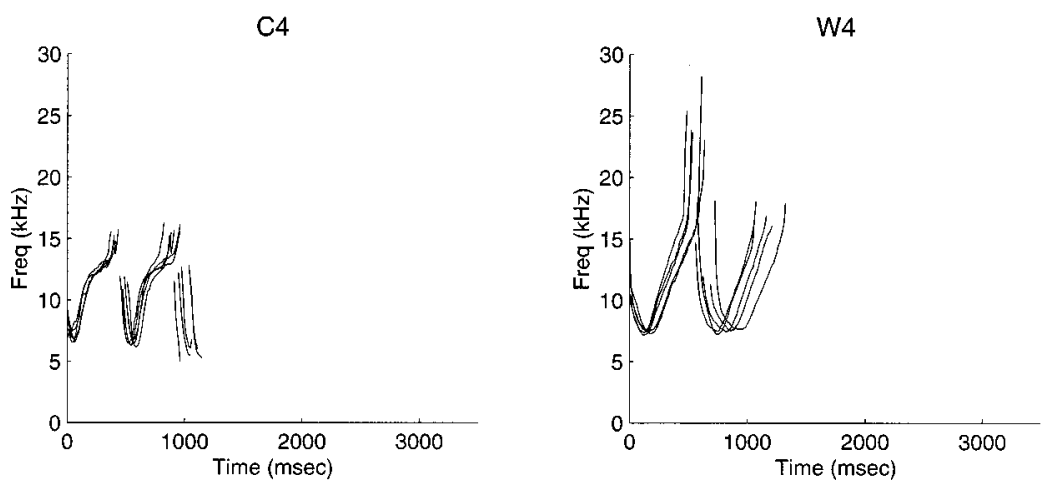

sure, referred to as contiguous flatness, is the ratio of the duration of the longest contiguous segment with $|y[n]| \leqslant \mu$ to the total gap-free duration of the $y[n]$. This measure quantifies the tendency to make whistles with one long unmodulated segment, opposed to several short unmodulated segments. A pathological whistle which gives $y[n]=2 \mu$ for $n$ odd and $y[n]=0$ for $n$ even would give roughly 0.50 for the total flatness, but only $1 / N$ for the contiguous flatness, since all the flat segments are only one sample long. For the signals analyzed in this study, these measures are generally correlated, with signals scoring high in one metric also scoring high in the other.

\section{Selection of flatness threshold}

The average of both the total flatness and contiguous flatness ratios over 20 whistles were computed as a function of $\mu$ for six animals (three pairwise comparisons) to determine an appropriate choice of threshold. The results of these comparisons are shown in Fig. 3. As expected, all of these figures show the proportion of whistle duration monotonically increasing with increasing threshold $\mu$. The proportion of whistle duration judged as flat asymptotically approaches 1 as $\mu$ gets very large, indicating that with a very broad threshold, all of almost every signal is considered flat. The trainers' whistles are more flat than most of the animals at almost any nonzero threshold.

For both the C6-W6 and C10-W10 comparisons in Fig. 3 , the captive animal ranks higher than the wild animal on both flatness metrics for any choice of the threshold $\mu$. Consequently, the results of this study are robust to different choices of threshold for a reasonable range of $\mu$. The C10W10 comparison data match the visual impressions obtained in Fig. 1. Specifically, the trainer's whistle is very flat, the captive whistle mostly flat, and the wild whistle highly modulated. Note that for $\mu>3 \times 10^{4}$, even a highly modulated whistle like W10 in Fig. 1 scores over 0.5 on the ratio of flat duration test. This indicates that choices of $\mu$ in this range are insufficiently discriminatory of features which appear unmodulated in the spectrograms and contours shown in Fig. 1. The $\mathrm{C} 4-\mathrm{W} 4$ comparison indicates the signals are roughly comparable in flatness over most meaningful values of $\mu$, with a slight edge in favor of the captive animal in the total flatness. However, it is clear from the bottom row of 

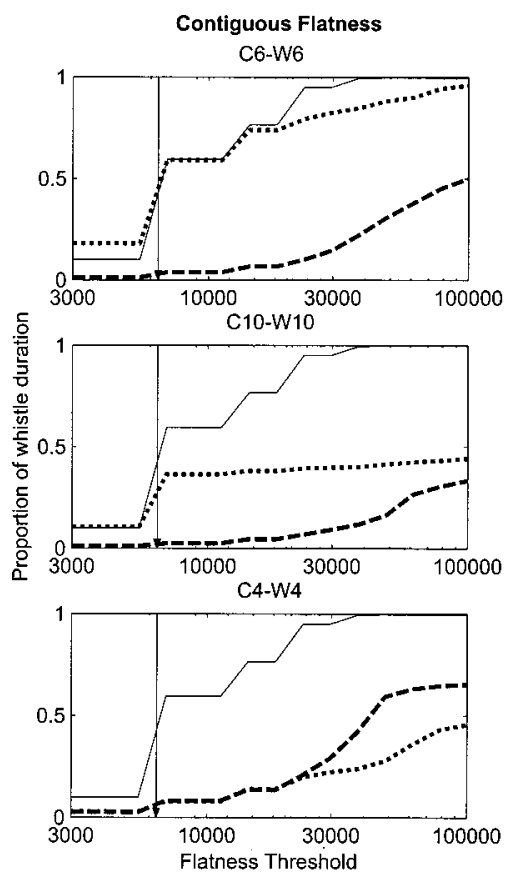
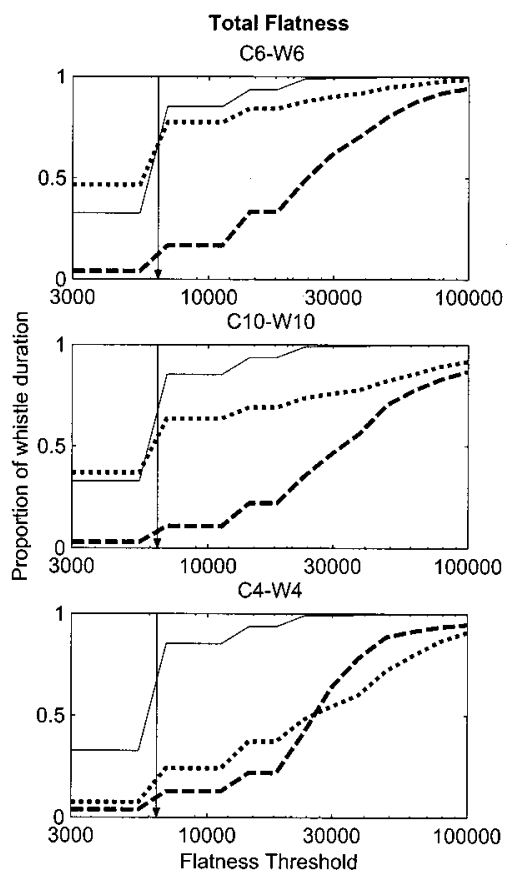

FIG. 3. Comparison of proportion of whistle duration judged to be flat as a function of varying the flatness threshold. This comparison was used to select one flatness threshold for the rest of the study. These flatness comparisons were made for three matched pairs of whistles from wild and captive dolphins, and the results are compared to the trainer's whistle. Solid lines indicate the trainer's whistle. Lines with short dashes represent captive born animals, and lines with long dashes represent wild born animals. Vertical arrows mark the 6400-Hz/s flatness threshold. The left column contains comparisons of contiguous flatness (duration of longest flat segment divided by total duration). The right column contains comparisons of total flatness (percentage of whistle scored as unmodulated).
Fig. 3 that neither of these signals is as unmodulated as the trainer's whistle.

Our working definition of a flat signal throughout the Results section is one whose slope is less than or equal to one frequency bin $(80 \mathrm{~Hz})$ per time block $(12.5 \mathrm{~ms})$, equivalent to a modulation rate of $80 \mathrm{~Hz} / 12.5 \mathrm{~ms}=6400 \mathrm{~Hz} / \mathrm{s}$. This is the minimum nonzero value possible for $\mu$, as it is the resolution limit for the STFT used in the experiment. Choosing $\mu=0$ is undesirable for the following reason. If the fundamental frequency of an unmodulated signal fell exactly between two FFT bins, e.g., $8040 \mathrm{~Hz}$, the resulting contour would jitter between these bins due to instrument noise, causing apparent changes of frequency at this modulation rate, causing the perfectly unmodulated whistle with 0 slope to be scored as if the slope were $6400 \mathrm{~Hz} / \mathrm{s}$. Hence, to avoid this problem the minimum reasonable threshold for an unmodulated signal is \pm 1 FFT bin/block $=6400 \mathrm{~Hz} / \mathrm{s}$. This value is indicated by a vertical arrow in Fig. 3.

\section{E. Statistical analysis}

Statistical testing of whether captive whistles differed from wild whistles within each pairing was performed using two techniques. The acoustic features were compared using a standard $t$-test (Zar, 1996). For the duration measurements (Tables III and IV), the observed data were transformed using a $\log$ transformation to ensure normality. The flatness measures (Tables V and VI) used an arcsine transformation to ensure normality.

The results were also analyzed using a nonparametric pooled sign test. This test compares the values of the acoustic feature for all possible captive and wild whistle pairs for each matched pair of dolphins. Since 20 whistles were sampled from each dolphin, and each wild whistle can be compared to all 20 of the matched captive whistles, there was a total of 400 pairwise comparisons of wild vs captive whistles for each pair. The total number of times the captive whistle had a greater value of the acoustic feature than the wild whistle was tallied. The binomial $p$-value indicates the probability of obtaining a result at least as extreme as the observed tally if the captive and wild populations had the same distribution for the feature in question. This probability was computed using the normal approximation to the binomial distribution for large numbers of trials (Zar, 1996). This test can be considered to be a Fisher permutation (Efron and Tibshirani, 1994) or exact (Conover, 1999) test on the result of a sign test on the pooled data. The advantage of using the number of sign test comparisons as a test statistic was that it allowed exact computation of the observed result's significance. This eliminated the need for evaluating large numbers of permutations of the data required by Fisher's test for most test statistics.

The computation of $p$-values for each result varied depending on the feature and table in question. For the durations (Tables III and IV), the null hypothesis was that the populations have the same durations. Consequently, the binomial $p$-values were computed for a two-tailed distribution. For the flatness measures (Tables V and IV), the null hypothesis was that the wild dolphin whistles were at least as flat as the captive dolphin whistles. The alternative hypothesis was that the captive dolphins have flatter whistles than the wild dolphins. Because of the polarity of these hypotheses, a onetailed distribution was used to compute the $p$-values for Tables V and VI.

\section{RESULTS}

Table II shows that the whistles of wild dolphins had much higher values of maximum frequency, end frequency, and frequency range than either whistles of captive dolphins or trainers' whistles. Visual inspection of the whistles in Fig. 1 showed the trainer's whistle was the least modulated in frequency compared to whistles of captive or wild dolphins, 
TABLE III. Total durations of whistles including interloop intervals. The means and variances in columns 3 and 4 reflect raw data values. The $t$-statistics and $p$-values in columns 5 and 6 were obtained using a log transformation $[\log (x)]$ to ensure normality. The counts of pairs in which total duration was greater for the wild member of the pair are listed in column 7. Column 8 lists the probability from the binomial distribution of obtaining a result at least as anamalous as the observed tally if the captive and wild dolphins are drawn from the same distribution.

\begin{tabular}{|c|c|c|c|c|c|c|c|}
\hline $\begin{array}{c}\text { Captive-wild } \\
\text { match }\end{array}$ & $\begin{array}{l}\text { Sample } \\
\text { size }\end{array}$ & $\begin{array}{l}\text { Mean } \\
(\mathrm{s})\end{array}$ & Variance & $t$ stat & $\begin{array}{c}t \text { stat } \\
p \text {-value }\end{array}$ & $\begin{array}{l}\text { Duration tally } \\
\text { (wild >captive) }\end{array}$ & $\begin{array}{c}\text { Binomial } \\
p \text {-value }\end{array}$ \\
\hline Trainer & 8 & 0.4156 & 0.0062 & & & & \\
\hline $\mathrm{C} 1$ & 20 & 1.1781 & 0.1141 & 1.09 & 0.28 & $137 / 400$ & $<10^{-6}$ \\
\hline W1 & 20 & 1.0725 & 0.1451 & & & & \\
\hline $\mathrm{C} 2$ & 20 & 1.2412 & 0.1151 & 0.04 & 0.96 & $221 / 400$ & 0.036 \\
\hline W2 & 20 & 1.2518 & 0.1552 & & & & \\
\hline $\mathrm{C} 3$ & 20 & 0.8675 & 0.37 & -1.13 & 0.27 & $261 / 400$ & $<10^{-6}$ \\
\hline W3 & 20 & 0.9194 & 0.0777 & & & & \\
\hline $\mathrm{C} 4$ & 20 & 1.1531 & 0.1423 & 1.81 & 0.079 & $160 / 400$ & $<10^{-4}$ \\
\hline W4 & 20 & 0.945 & 1.1002 & & & & \\
\hline $\mathrm{C} 5$ & 20 & 0.9431 & 0.0118 & -1.48 & 0.15 & $250 / 400$ & $<10^{-6}$ \\
\hline W5 & 20 & 1.06 & 0.0682 & & & & \\
\hline C6 & 20 & 0.54 & 0.0134 & -3.74 & $<10^{-6}$ & $284 / 400$ & $<10^{-6}$ \\
\hline W6 & 20 & 1.555 & 1.0701 & & & & \\
\hline $\mathrm{C} 7$ & 20 & 0.9818 & 0.128 & -2.63 & 0.012 & $278 / 400$ & $<10^{-6}$ \\
\hline W7 & 20 & 1.355 & 0.2464 & & & & \\
\hline $\mathrm{C} 8$ & 20 & 0.7662 & 0.036 & 0.93 & 0.36 & $156 / 400$ & $<10^{-4}$ \\
\hline W8 & 20 & 0.71 & 0.0575 & & & & \\
\hline C9 & 20 & 0.4064 & 0.0036 & -12.5 & $<10^{-6}$ & $400 / 400$ & $<10^{-6}$ \\
\hline W9 & 20 & 0.905 & 0.0496 & & & & \\
\hline $\mathrm{C} 10$ & 20 & 0.7731 & 0.0015 & -6.17 & $<10^{-6}$ & $380 / 400$ & $<10^{-6}$ \\
\hline W10 & 20 & 1.3038 & 0.1541 & & & & \\
\hline
\end{tabular}

and that the captive whistle was less modulated than the wild whistle. The measurements of frequency range of the trainer and dolphin whistles followed a similar pattern. The trainers' whistles had the narrowest frequency range, and the wild whistles had the widest frequency range. Our initial hypoth- esis suggested the broader frequency range corresponded to a higher degree of frequency modulation, indicating that wild dolphin whistles had more frequency modulation than whistles of dolphins born in a captive environment where an unmodulated trainer's whistle was heard. To verify this sug-

TABLE IV. Gap-free whistle durations excluding interloop intervals. The means and variances in columns 3 and 4 reflect raw data values. The $t$-statistics and $p$-values in columns 5 and 6 were obtained using a log transformation $[\log (x)]$ to ensure normality. The counts of pairs in which gap-free duration was greater for the wild member of the pair are listed in column 7. Column 8 lists the probability from the binomial distribution of obtaining a result at least as anomalous as the observed tally if the captive and wild dolphins are drawn from the same distribution.

\begin{tabular}{|c|c|c|c|c|c|c|c|}
\hline $\begin{array}{c}\text { Captive-wild } \\
\text { match }\end{array}$ & $\begin{array}{l}\text { Sample } \\
\text { size }\end{array}$ & $\begin{array}{c}\text { Mean } \\
(\mathrm{s})\end{array}$ & Variance & $t$ stat & $\begin{array}{c}t \text { stat } \\
p \text {-value }\end{array}$ & $\begin{array}{l}\text { Duration tally } \\
\text { (wild }>\text { captive) }\end{array}$ & $\begin{array}{c}\text { Binomial } \\
p \text {-value }\end{array}$ \\
\hline Trainer & 8 & 0.4156 & 0.0062 & & & & \\
\hline $\mathrm{C} 1$ & 20 & 1.1651 & 0.1154 & 3.36 & 0.0018 & $80 / 400$ & $<10^{-6}$ \\
\hline W1 & 20 & 0.8424 & 0.0525 & & & & \\
\hline $\mathrm{C} 2$ & 20 & 1.2356 & 0.116 & 2.48 & 0.017 & $102 / 400$ & $<10^{-6}$ \\
\hline W2 & 20 & 0.9987 & 0.121 & & & & \\
\hline C3 & 20 & 0.8569 & 0.5596 & 0.57 & 0.57 & $220 / 400$ & 0.046 \\
\hline W3 & 20 & 0.6799 & 0.0572 & & & & \\
\hline $\mathrm{C} 4$ & 20 & 0.9837 & 0.1097 & 0.82 & 0.42 & $205 / 400$ & 0.62 \\
\hline W4 & 20 & 0.8988 & 0.0828 & & & & \\
\hline $\mathrm{C} 5$ & 20 & 0.9294 & 0.016 & -1.65 & 0.11 & $251 / 400$ & $<10^{-6}$ \\
\hline W5 & 20 & 1.06 & 0.0682 & & & & \\
\hline C6 & 20 & 0.54 & 0.0134 & -2.61 & 0.013 & $278 / 400$ & $<10^{-6}$ \\
\hline W6 & 20 & 0.9612 & 0.3145 & & & & \\
\hline $\mathrm{C} 7$ & 20 & 0.6274 & 0.0645 & -5.75 & $<10^{-5}$ & $363 / 400$ & $<10^{-6}$ \\
\hline W7 & 20 & 1.3106 & 0.2394 & & & & \\
\hline $\mathrm{C} 8$ & 20 & 0.7662 & 0.036 & 0.98 & 0.33 & $154 / 400$ & $<10^{-5}$ \\
\hline W8 & 20 & 0.71 & 0.0575 & & & & \\
\hline C9 & 20 & 0.4064 & 0.0036 & -11.41 & $<10^{-6}$ & $400 / 400$ & $<10^{-6}$ \\
\hline W9 & 20 & 0.8041 & 0.0339 & & & & \\
\hline $\mathrm{C} 10$ & 20 & 0.7731 & 0.0015 & -5.83 & $<10^{-6}$ & $380 / 400$ & $<10^{-6}$ \\
\hline W10 & 20 & 1.2662 & 0.1037 & & & & \\
\hline
\end{tabular}


TABLE V. Total flatness measurements (percentage of whistle flatness) for signature whistles of wild and captive-born animals. The $t$-statistics and $p$-values in columns 5 and 6 were obtained using an arcsine transformation $[\arcsin (x)]$ to ensure normality. The counts of pairs in which total flatness was greater for the captive member of the pair are listed in column 7. Column 8 lists the probability from the binomial distribution of obtaining a result at least as anomalous as the observed tally if the captive and wild dolphins are drawn from the same distribution.

\begin{tabular}{|c|c|c|c|c|c|c|c|}
\hline $\begin{array}{c}\text { Captive-wild } \\
\text { match }\end{array}$ & $\begin{array}{l}\text { Sample } \\
\text { size }\end{array}$ & Mean & Variance & $t$ stat & $\begin{array}{c}t \text {-stat } \\
p \text {-value }\end{array}$ & $\begin{array}{c}\text { Flat tally } \\
\text { (captive }>\text { wild) }\end{array}$ & $\begin{array}{c}\text { Binomial } \\
p \text {-value }\end{array}$ \\
\hline Trainer & 8 & 0.853 & 0.0225 & & & & \\
\hline $\mathrm{C} 1$ & 20 & 0.294 & $4.77 E-03$ & 2.44 & 0.0095 & $275 / 400$ & $<10^{-6}$ \\
\hline W1 & 20 & 0.246 & $2.75 E-03$ & & & & \\
\hline $\mathrm{C} 2$ & 20 & 0.235 & $1.62 E-03$ & 14.53 & $<10^{-6}$ & $400 / 400$ & $<10^{-6}$ \\
\hline W2 & 20 & 0.0525 & $6.26 E-04$ & & & & \\
\hline C3 & 20 & 0.197 & $4.14 E-03$ & 1.2 & 0.12 & $219 / 400$ & 0.029 \\
\hline W3 & 20 & 0.173 & $5.24 E-03$ & & & & \\
\hline $\mathrm{C} 4$ & 20 & 0.24 & $1.33 E-03$ & 13.04 & $<10^{-6}$ & $398 / 400$ & $<10^{-6}$ \\
\hline W4 & 20 & 0.128 & $2.90 E-04$ & & & & \\
\hline $\mathrm{C} 5$ & 20 & 0.613 & $4.37 E-03$ & 16.93 & $<10^{-6}$ & $400 / 400$ & $<10^{-6}$ \\
\hline W5 & 20 & 0.299 & $2.16 E-03$ & & & & \\
\hline C6 & 20 & 0.777 & $2.80 E-03$ & 31.79 & $<10^{-6}$ & $400 / 400$ & $<10^{-6}$ \\
\hline W6 & 20 & 0.116 & $2.40 E-03$ & & & & \\
\hline $\mathrm{C} 7$ & 20 & 0.115 & $4.08 E-03$ & 3.57 & $<10^{-3}$ & $313 / 400$ & $<10^{-6}$ \\
\hline W7 & 20 & 0.0601 & $7.36 E-04$ & & & & \\
\hline $\mathrm{C} 8$ & 20 & 0.689 & $5.29 E-03$ & 5.98 & $<10^{-6}$ & $377 / 400$ & $<10^{-6}$ \\
\hline W8 & 20 & 0.525 & $9.45 E-03$ & & & & \\
\hline C9 & 20 & 0.355 & $1.10 E-02$ & 10.82 & $<10^{-6}$ & $400 / 400$ & $<10^{-6}$ \\
\hline W9 & 20 & 0.119 & $9.14 E-04$ & & & & \\
\hline $\mathrm{C} 10$ & 20 & 0.636 & $6.58 E-04$ & 40.71 & $<10^{-6}$ & $400 / 400$ & $<10^{-6}$ \\
\hline W10 & 20 & 0.106 & $1.30 E-03$ & & & & \\
\hline
\end{tabular}

gestion, we conducted a quantitative analysis of frequency modulation using the signal processing techniques described in the Methods section.

Figure 2 shows five contours selected randomly from the 20 whistles analyzed from three of the ten captive-wild pairs used for the comparisons in this paper. These contours were simply aligned by starting each whistle at time 0 . The C6-W6 comparison was selected to illustrate a particularly unmodulated captive whistle, C10-W10 was more typical, and $\mathrm{C} 4-\mathrm{W} 4$ was the one example of a wild animal that had

TABLE VI. Contiguous flatness measurements (ratio comparing the duration of the longest contiguous flat segment to the total duration) for signature whistles of wild and captive-born animals. The $t$-statistics and $p$-values in columns 5 and 6 were obtained using an $\operatorname{arcsine}$ transformation $[\arcsin (x)]$ to ensure normality. The counts of pairs in which contiguous flatness was greater for the captive member of the pair are listed in column 7. Column 8 lists the probability from the binomial distribution of obtaining a result at least as anomalous as the observed tally if the captive and wild dolphins are drawn from the same distribution.

\begin{tabular}{|c|c|c|c|c|c|c|c|}
\hline $\begin{array}{c}\text { Captive-wild } \\
\text { match }\end{array}$ & $\begin{array}{l}\text { Sample } \\
\text { size }\end{array}$ & Mean & Variance & $t$ stat & $\begin{array}{c}t \text {-stat } \\
p \text {-value }\end{array}$ & $\begin{array}{c}\text { Flat tally } \\
\text { (captive }>\text { wild) }\end{array}$ & $\begin{array}{c}\text { Binomial } \\
p \text {-value }\end{array}$ \\
\hline Trainer & 8 & 0.595 & 0.118 & & & & \\
\hline $\mathrm{C} 1$ & 20 & 0.0763 & $6.60 E-04$ & 1.6 & 0.059 & $272 / 400$ & $<10^{-6}$ \\
\hline W1 & 20 & 0.0642 & $6.71 E-04$ & & & & \\
\hline $\mathrm{C} 2$ & 20 & 0.0821 & $5.77 E-04$ & 13.34 & $<10^{-6}$ & $400 / 400$ & $<10^{-6}$ \\
\hline W2 & 20 & 0.0163 & $3.04 E-05$ & & & & \\
\hline $\mathrm{C} 3$ & 20 & 0.0974 & $3.22 E-03$ & 2.67 & 0.0055 & $275 / 400$ & $<10^{-6}$ \\
\hline W3 & 20 & 0.0617 & $6.61 E-04$ & & & & \\
\hline $\mathrm{C} 4$ & 20 & 0.0777 & $1.14 E-03$ & -0.69 & 0.25 & $186 / 400$ & 0.92 \\
\hline W4 & 20 & 0.0825 & $6.70 E-04$ & & & & \\
\hline $\mathrm{C} 5$ & 20 & 0.363 & 0.237 & 9.67 & $<10^{-6}$ & $400 / 400$ & $<10^{-6}$ \\
\hline W5 & 20 & 0.0737 & $5.76 E-04$ & & & & \\
\hline C6 & 20 & 0.591 & 0.02 & 19.87 & $<10^{-6}$ & $400 / 400$ & $<10^{-6}$ \\
\hline W6 & 20 & 0.0376 & $3.53 E-04$ & & & & \\
\hline $\mathrm{C} 7$ & 20 & 0.0547 & $1.13 E-03$ & 4.26 & $<10^{-4}$ & $333 / 400$ & $<10^{-6}$ \\
\hline W7 & 20 & 0.021 & $3.12 E-04$ & & & & \\
\hline $\mathrm{C} 8$ & 20 & 0.277 & $9.59 E-03$ & 2.85 & 0.0035 & $288 / 400$ & $<10^{-6}$ \\
\hline W8 & 20 & 0.2 & $5.81 E-03$ & & & & \\
\hline $\mathrm{C} 9$ & 20 & 0.172 & $5.28 E-03$ & 8.02 & $<10^{-6}$ & $395 / 400$ & $<10^{-6}$ \\
\hline W9 & 20 & 0.0541 & $4.39 E-04$ & & & & \\
\hline $\mathrm{C} 10$ & 20 & 0.364 & $6.89 E-04$ & 59.28 & $<10^{-6}$ & $400 / 400$ & $<10^{-6}$ \\
\hline W10 & 20 & 0.0248 & $5.56 E-05$ & & & & \\
\hline
\end{tabular}


a longer flat segment than its captive pair. We discuss the C6 and $\mathrm{C} 10$ whistles in more detail to illustrate differences between our total flatness and contiguous flatness measures. The longest unmodulated segments of the five C6 whistles had durations of $181.7,342.4,232.3,329.8$, and $304.5 \mathrm{~ms}$. The total flatness scores for these C6 whistles were 46.9\%, $41.3 \%, 64.1 \%, 60.9 \%$, and $61.4 \%$. The $\mathrm{C} 10$ whistles, on the other hand, had two relatively flat sections at different frequencies. Even though the $\mathrm{C} 10$ whistles scored 58.7\%$64.7 \%$ in total flatness, their longest unmodulated segments were 221.5-295.6 ms, producing contiguous flatness scores of $27.7 \%-39.3 \%$. Both total flatness and contiguous flatness measures were retained for later analysis since they measure different features associated with unmodulated whistles.

Some signature whistles had a structure with repeated segments, while others did not contain repetitions of a contour. For example, the five whistles of C6 and C10 illustrated in Fig. 2 did not have segments that were repeated a variable number of times. On the other hand, the whistles of W6 and W10 did repeat a variable number of times. The whistles from W6 had between three and five repetitions of a basic upsweep, while four of the five versions of W10's contour had two repetitions. The fifth W10 contour had three repetitions, as can be seen by the single contour line between 1000 and $2000 \mathrm{~ms}$ on the middle right cell of Fig. 2. This distribution of repeated vs nonrepeated whistles was similar in the wild and captivity. Of the 81 Sarasota dolphins analyzed in Sayigh (1992) 22 (27\%) have nonrepetitive whistles (Tyack and Sayigh, 1997). Of the 126 captive dolphins in the Caldwell et al. (1990) sample, 25 (20\%) were not recorded repeating segments. In general, nonrepetitive signature whistles tended to be shorter in duration than those with repeated elements, but since the proportions of these whistle types were similar in captive and wild settings, there was no a priori reason to expect a systematic difference in duration across our matched pairs.

The first statistical tests we performed compared the durations of whistles from wild and captive dolphins. We had no a priori predictions about differences in whistle duration, and the comparisons of whistle durations yielded mixed results depending on the statistic measured and test used. For total whistle duration, including gaps (Table III), the captive dolphin had shorter whistles in seven out of the ten pairs. The $t$-test only showed significant $(p \leqslant 0.05)$ differences for four of the ten pairs, and in all four of the significant pairs, the captive dolphin whistles were shorter. The binomial test (column 7 of Table III) also indicated that the captive dolphin had shorter whistles for seven of the ten pairs, but the binomial test showed a significant difference $(p \leqslant 0.05)$ in whistle duration for all ten pairs (column 8 of Table III). Similar results occurred for the durations excluding any silent periods in the whistle (Table IV). Comparison of mean durations (column 3 of Table IV) indicated that five pairs showed the wild dolphin having longer whistles, and five pairs showed the captive dolphin having longer whistles. Six of the pairs generated significant $t$-test values at $p<0.05$. Four of the six significant pairs had longer whistles for the wild dolphin. The binomial test indicated that eight of the ten pairs had a highly significant $(p<0.001)$ difference in length. Of these eight highly significant pairs, five had longer whistles for the wild dolphin. Pooling all binomial tests showed a significant $\left(p<10^{-6}\right)$ difference in the durations for both total duration and gap-free duration, with wild dolphins tending to have longer whistles.

The primary hypothesis of this study was that dolphins born in a captive setting where they hear trainers' whistles would have flatter whistles than matched animals that never heard such whistles. The whistles of captive-born animals were significantly flatter than whistles of wild-born animals, especially for the measure of total flatness. Comparison of the mean total flatness between wild and captive pairs (column 3 in Table V) showed that the captive animal in all ten pairs had the higher mean total flatness. In $9 / 10$ of these pairs, the difference in total flatness tested by a $t$-test was significant to the $p<0.05$ level; the exception was the C3-W3 comparison. Comparison of the mean contiguous flatness between wild and captive pairs (column 3 in Table VI) showed that the contiguous flatness was greater for the captive-born animals than the wild-born animals in 9/10 of the pairs. The exception was the $\mathrm{C} 4-\mathrm{W} 4$ pair; the differences were not statistically significant for this $\mathrm{C} 4-\mathrm{W} 4$ pair and the $\mathrm{C} 1-\mathrm{W} 1$ pair judging by the $t$-test $(p=0.05)$. All other pairs, in which contiguous flatness was greater for the captive member of the pair, were significant to the $p<0.05$ level for the $t$-test.

The binomial statistics also supports the hypothesis that wild dolphins produce more highly modulated whistles than their captive counterparts. Examining total flatness, all ten pairings produced tallies (column 7 of Table V) where more than half of the comparisons indicated a less modulated whistle for the captive animal. For contiguous flatness, 9/10 of the pairings had a majority of the comparisons with a flatter whistle for the captive animal (column 7 of Table VI). In fact, the captive animals had less modulated whistles by perfect tallies of $400 / 400$ for $5 / 10$ of the total flatness pairings and $4 / 10$ of the contiguous flatness pairings. These perfect scores indicate that for those pairs of animals, every captive dolphin whistle was less modulated than every wild dolphin whistle. The $p$-values for the comparison tallies (column 8 of Tables V and VI) also supported our primary hypothesis. Nine of the ten pairs had highly significant ( $p$ $<10^{-6}$ ) tallies for both total flatness and contiguous flatness, and the only insignificant difference for contiguous flatness involved the only pair with a higher flatness score for wild animals. Pooling all binomial tests showed a significant ( $p$ $<10^{-6}$ ) difference in both total flatness and continuous flatness, with captive dolphins tending to have less modulated whistles.

The most conservative statistical analysis would treat each matched pair of animals as a unit of analysis for statistical testing $(n=10)$. For the total flatness measure, all ten of the captive members of the pair had higher mean flatness values and higher flat tallies for the binomial test. The significance of this 10/10 result as a binomial test was $p$ $<0.001$. For contiguous flatness, the mean flatness score and flat tallies were higher for captives in 9/10 of the pairs, giving an overall significance of $p=0.0107$. Consequently, we saw that all four of our overall statistical tests using the pair 

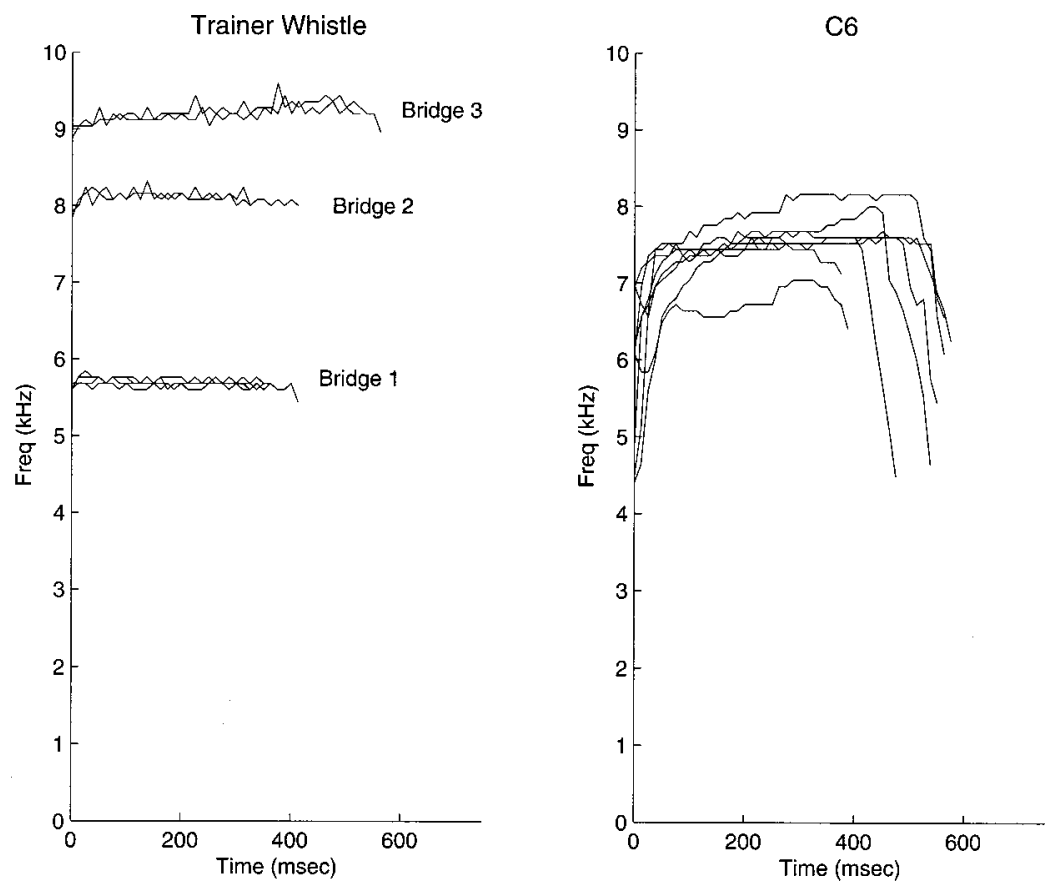

FIG. 4. Contour comparisons of eight examples of the whistles of three trainers and eight whistles from the dolphin, C6, whose whistle was most similar to the trainer's whistles, C6. The trainers' whistles and whistles from C6 were aligned by starting all whistles at time 0 .

as the unit of analysis (mean flatness and flat tallies for both flatness measures) yielded a significant result for the combined data set. The combined results support the hypothesis that the captive dolphins overall have less modulated, flatter whistles than wild dolphins.

We have shown that the whistles of captive dolphins show a much better match than do wild dolphins to the lack of frequency modulation seen in trainers' whistles. How similar were the whistles of captive dolphins to the timing and frequency of the trainer's whistle? Figure 4 shows contours of three different trainers' whistles along with the whistles of $\mathrm{C} 6$, the captive dolphin with a whistle closest to the trainer's whistle in terms of the modulation measures. This figure shows that while all trainers' whistles were unmodulated, the three different whistles used by the eight trainers tended to have a different absolute frequency. The whistle of C6 was closest to the intermediate trainer's whistle. Comparing the contours of C6's whistles (all of which contain one loop) to the trainer's whistle, the whistles appeared similar in overall flatness and duration. The means of the contiguous flatness within C6's and the trainer's whistles were not significantly different $($ C6 mean $=0.591 n$ $=20$; trainer mean $=0.595 n=8 ; t=-0.55 ; p=0.58$ ). However, the trainers' whistles tended to have a higher mean total flatness over the entire call than the whistles of C6 (C6 mean $=0.775$; trainer mean $=0.853 ; t=-2.73 ; p=0.011)$. Because C6 had a one-loop signature whistle, the durations were measured from the start to end of the whistle; since there were no gaps, the gap-free duration equaled the total duration. The mean duration of trainer's whistles $(n=8)$ was $0.415 \mathrm{~s}$, while the mean duration of C6's whistles $(n=20)$ was $0.540 \mathrm{~s}$. A $p$-value of 0.013 showed that the trainer's whistle was significantly shorter than C6's whistles.

\section{DISCUSSION}

The results of this comparison support the hypothesis that young dolphins born hearing a synthetic whistle in cap- tivity incorporate acoustic features of this synthetic whistle into their own signature whistles. However, there are several minor imperfections in the study design that suggest benefits for future work to reach a more definitive conclusion. Recordings from wild and captive dolphins were not made in exactly the same contexts, and Janik et al. (1994) demonstrated slight changes in frequency parameters of signature whistles in different contexts in captivity. On the other hand, both wild (Sayigh et al., 1990) and captive (Caldwell et al., 1990) dolphins produce signature whistles with similar overall contours when stranded in air vs swimming freely, and Sayigh et al. (1990) reported that the contour of whistles emitted by Sarasota dolphins recorded in rafts was similar to those emitted from the same animal while freely swimming in a net corral and immediately after release. We know of no results suggesting that the context of restraint would reduce the probability of producing unmodulated whistles, but it would be a better study design to control for behavioral context.

Another problem with this study was that all of the captive dolphins came from one facility. This complicates interpretation of the results where some calves were born soon after other calves. For example, as Table I indicates, Samantha and Noel were born in the same year, and Tori, Sundance, and PJ were born in the same year. These dolphins were all born in the same pool and were all in the pool together for some months after the births of Tori, Sundance, and PJ. This means that, for example, if Samantha had imitated the trainer's whistle and was producing an unmodulated whistle, we cannot discriminate whether Noel, Tori, etc. developed unmodulated whistles through imitating the trainers or imitating Samantha. However, even if this were happening, the data clearly indicate that young dolphin calves are incorporating features of acoustic models prominent in their natal environment.

A third potential problem with interpreting these results stems from a limitation in the synthetic models provided to 
young calves: the only synthetic whistle tested has been unmodulated whistles used by trainers. Captive dolphins are raised in a more confined and reverberant environment than wild dolphins. It is plausible that this reverberant environment played a role in the captive animals developing shorter or less modulated whistles than their wild counterparts. However, the impact of reverberation is difficult to assess without a clear understanding of the function of the whistles and which acoustic features are perceptually relevant. A highly modulated whistle would be better for detecting and localizing the source in a reverberant environment. For communication and discrimination, the impact of the environment is less clear. One possible hypothesis is that the reverberant tank environment would encourage young dolphins to develop unmodulated whistles at a nonresonant frequency to minimize the impact of the resonances of the tank on the amplitude of the signal. Consideration of the physical acoustics and the modes of the tank argues against this hypothesis. For the $5-10-\mathrm{kHz}$ frequency range, the resonances of the pool are less than $30 \mathrm{~Hz}$ apart in frequency. The observed captive dolphin whistles do not demonstrate less than $30 \mathrm{~Hz}$ of variability, so this hypothesis is unlikely to affect modulation of whistles in resonant pools. It is difficult to say conclusively how the reverberation would impact the dolphins' ability to discriminate different fundamental contours. One way to control for these effects of reverberation would be to compare captive dolphins from similar pools, one group of which has been exposed to trainers' whistles and another group of which has never heard them.

All of the above problems would be solved by an expanded study of similar design in which several different facilities were tested, with each new calf in each new facility being exposed to a novel synthetic whistle that is not present in the pre-exposure whistle repertoire of dolphins in the natal pool. In this kind of multifacility setting, it would also be possible to test for the social vs the acoustic salience of the model sound. When trainers blow their whistle, they are signaling to a dolphin that it has performed the correct behavior and can return to station for a reward. Dolphins respond strongly and immediately to this signal. In the Top Deck pool where the captive dolphins in this study were recorded, the trainers only blow their whistle during limited training sessions or presentations to the public. The trainer's whistle is much less frequent than many of the dolphin whistles heard in the pool. This suggests that the intense reinforcing quality of the signal, and the strong predictable responses it evokes, may be as important as any purely acoustic qualities it may have. This hypothesis could be tested using a yoked control design in which the trainers used their whistles for training in one pool, while the exact same pattern of acoustic presentation of whistles, with no associated training or reinforcement, was presented in another pool.

An expanded study with a larger sample size would also be able to address alternative hypotheses of how dolphin age and length of time spent in captivity may affect the acoustic structure of whistles. It is possible that older dolphins exposed to the trainer's whistle for several years would have incorporated more features of the trainer's whistle into their own whistles, but our results do not support this hypothesis. The oldest captive dolphins, C3 (15 years) and C7 (35 years), had the lowest total flatness scores in the captive category. This agrees with the results of Caldwell et al. (1990), who report a significant increase in frequency modulation with age in captive bottlenose dolphins. Studies of dolphins born in the wild and brought into captivity at varying ages could address the question of whether there is a sensitive period after which dolphins are less likely to incorporate acoustic features of the trainers' whistles. Tyack (1986) presented evidence that signature whistles of two wild-born dolphins brought into captivity at about 5 years of age maintained their relatively modulated whistle contours for up to 7 years in captivity, even though they occasionally imitated the trainer's whistle.

This study stemmed from a serendipitous ability to use the trainer's whistle as a synthetic stimulus presented during whistle development. The evidence that calves match the trainers' whistles not only provides strong evidence for vocal learning in whistle development, but also suggests that more controlled and systematic presentation of synthetic stimuli is a promising experimental paradigm for further studies on the role of learning in vocal development of marine mammals.

\section{ACKNOWLEDGMENTS}

J.R.B. gratefully acknowledges the support of the National Science Foundation Ocean Sciences CAREER Award 9733391. P.L.T. acknowledges the support of the Office of Naval Research Grant N00014-87-K-0236 and NIH Grant 5 R29 NS25290 for supporting the collection of the data used in this study and NIH Grant R01 DC04191 for support in preparation of the manuscript. The authors would also like to thank the two anonymous reviewers for their helpful comments on an earlier manuscript draft. This is Contribution Number 10040 from the Woods Hole Oceanographic Institution and Contribution Number 990902 from the University of Massachusetts Dartmouth School for Marine Science and Technology. All research performed complied with all current U.S. laws and permits.

Buck, J. R., and Tyack, P. L. (1993). “A quantitative measure of similarity for Tursiops truncatus signature whistles," J. Acoust. Soc. Am. 94, 24972506.

Caldwell, M. C., and Caldwell, D. K. (1965). "Individualized whistle contours in bottlenosed dolphins (Tursiops truncatus)," Nature (London) 207, 434-435.

Caldwell, M. C., and Caldwell, D. K. (1972). "Vocal mimicry in the whistle mode by an Atlantic bottlenosed dolphin," Cetology 9, 1-8.

Caldwell, M. C., Caldwell, D. K., and Tyack, P. L. (1990). "A review of the signature whistle hypothesis for the Atlantic bottlenose dolphin, Tursiops truncatus," in The Bottlenose Dolphin: Recent Progress in Research, edited by S. Leatherwood and R. Reeves (Academic, San Diego), pp. 199234.

Conover, W. J. (1999). Practical Nonparametric Statistics, 3rd ed. (Wiley, New York).

Efron, B., and Tibshirani, R. J. (1994). An Introduction to the Bootstrap (CRC Press, Boca Raton).

Evans, W. E. (1967). "Vocalization among marine mammals," in Marine Bioacoustics, edited by W. N. Tavolga (Pergamon, Oxford), Vol. 2, pp. 159-186.

Herman, L. M. (1980). "Cognitive characteristics of dolphins," in Cetacean Behavior: Mechanisms and Functions, edited by L. M. Herman (WileyInterscience, New York), pp. 363-429. 
Janik, V. M., Dehnhardt, G., and Todt, D. (1994). "Signature whistle variations in a bottlenosed dolphin, Tursiops truncatus," Behav. Ecol. Sociobiol. 35, 243-248.

Janik, V. M., and Slater, P. J. B. (1997). "Vocal learning in mammals," Adv. Study Behav. 26, 59-99.

Janik, V. M., and Slater, P. J. B. (1998). "Context-specific use suggests that bottlenose dolphin signature whistles are cohesion calls," Anim. Behav. 56, 829-838.

Oppenheim, A. V., Schafer, R. W., with Buck, J. R. (1999). Discrete-time Signal Processing, 2nd ed. (Prentice-Hall, Englewood Cliffs, NJ).

Owren, M. J., Dieter, J. A., Seyfarth, R. M., and Cheney, D. L. (1993). "Vocalizations of rhesus (Macaca mulatta) and Japanese (Macaca fuscata) macaques cross-fostered between species show evidence of only limited modification," Dev. Psychobiol. 26(7), 389-406.

Reiss, D., and McCowan, B. (1993). "Spontaneous vocal mimicry and production by bottlenose dolphins (Tursiops truncatus): Evidence for vocal learning," J. Comp. Psych. 107, 301-312.

Richards, D. G., Wolz, J. P., and Herman, L. M. (1984). "Vocal mimicry of computer-generated sounds and vocal labeling of objects by a bottlenosed dolphin, Tursiops truncatus," J. Comp. Psych. 8, 10-28.

Sayigh, L. S. (1992). "Development and functions of signature whistles of free-ranging bottlenose dolphins, Tursiops truncatus," Ph.D. dissertation, MIT/WHOI Joint Ph.D. Program, Woods Hole, MA.

Sayigh, L. S., Tyack, P. L., Wells, R. S., and Scott, M. D. (1990). "Signature whistles of free-ranging bottlenose dolphins, Tursiops truncatus: Stability and mother-offspring comparisons," Behav. Ecol. Sociobiol. 26, 247-260.
Sayigh, L. S., Tyack, P. L., Wells, R. S., Scott, M. D., and Irvine, A. B. (1995). "Sex difference in whistle production in free-ranging bottlenose dolphins, Tursiops truncatus," Behav. Ecol. Sociobiol. 36, 171-177.

Sayigh, L. S., Tyack, P. L., Wells, R. S., Solow, A., Scott, M. D., and Irvine, A. B. (1999). "Individual recognition in wild bottlenose dolphins: A field test using playback experiments," Anim. Behav. 57, 41-50.

Scott, M. D., Wells, R. S., and Irvine, A. B. (1990), "A long-term study of bottlenose dolphins on the west coast of Florida," in The Bottlenose Dolphin Recent Progress in Research, edited by S. Leatherwood and R. Reeves (Academic, San Diego), pp. 235-244.

Sigurdson, J. (1993). "Whistles as a communication medium," in Language and Communication: Comparative Perspectives, edited by H. L. Roitblat, L. M. Herman, and P. Nachtigall (Erlbaum, Hillsdale, NJ), pp. 153-173.

Smolker, R. A., Mann, J., and Smuts, B. B. (1993). "Use of signature whistles during separations and reunions by wild bottlenose dolphin mothers and infants," Behav. Ecol. Sociobiol. 33, 393-402.

Tyack, P. (1985). "An optical telemetry device to identify which dolphin produces a sound," J. Acoust. Soc. Am. 78, 1892-1895.

Tyack, P. (1986). "Whistle repertoires of two bottlenosed dolphins, Tursiops truncatus: Mimicry of signature whistles?" Behav. Ecol. Sociobiol. 18, 251-257.

Tyack, P. L., and Sayigh, L. S. (1997). "Vocal learning in cetaceans," in Social Influences on Vocal Development, edited by C. T. Snowdon and M. Hausberger (Cambridge University Press, Cambridge), pp. 208-233.

Zar, J. H. (1996). Biostatistical Analysis, 3rd ed. (Prentice-Hall, Upper Saddle River, NJ). 